\section{Does It Pay To Be Transparent? International Evidence from Central Bank Forecasts}

\author{
Georgios Chortareas, David Stasavage, and \\ Gabriel Sterne
}

\section{INTRODUCTION}

T he past decade witnessed an increased interest in the institutional framework of monetary policy. The benefits of central bank independence have been demonstrated in much academic research and have become conventional wisdom among policymakers. ${ }^{1}$ New questions have emerged, however, about the institutional characteristics of central banks and their effect on economic performance; recent analyses have attempted to identify optimal degrees of independence, accountability, and transparency in monetary policy.

Relative to the abundant literature on the effects of central bank independence, only limited research exists so far on the issues of transparency and accountability in monetary policy. Furthermore, empirical analyses have mostly focused on financial markets and used time-series data. ${ }^{2}$ In this paper we examine how monetary policy transparency is associated with inflation and output in a crosssection of 87 countries. We use a particular concept of transparency that relates to the detail in which central banks publish economic forecasts (henceforth "transparency in forecasting"). We employ a

Georgios Chortareas is an economist in the International Economic Analysis Division, Bank of England. David Stasavage is a lecturer in the Department of International Relations, London School of Economics Gabriel Sterne is an economist in the International Economic Analysis Division, Bank of England. The authors thank the following for their helpful comments and suggestions: Andrew Bailey, Lawrence Ball,

Alec Chrystal, Rebecca Driver, Petra Geraats, Charles Goodhart, Andrew Haldane, Andrew Hauser, Marion Kohler, Kenneth Kuttner, Lavan Mahadeva, Adam Posen, Daniel Thornton, Peter Westaway, Mark Zelmer, and the participants of the 26th Annual Economic Policy Conference of the Federal Reserve Bank of St Louis, Bank of England seminars, the 2001 Eastern Economic Association meetings, the 2001 Public Choice Society meetings, and the 2001 Congress of the European Economic Association. The views expressed are those of the authors and not necessarily those of the Bank of England

(c) 2002, The Federal Reserve Bank of St. Louis. new data set based on a survey conducted by Fry, Julius, Mahadeva, Roger, and Sterne (2000) (henceforth FJMRS). To our knowledge these are the only data covering transparency in monetary policy across such a wide cross-section of countries.

Our results show that a higher degree of transparency in monetary policy is associated with lower inflation. The relationship is robust to various econometric specifications and holds regardless of whether the domestic nominal anchor is based more on an inflation or a money target. In contrast, our results suggest that the publication of forecasts has no significant impact on inflation in countries that target the exchange rate. In addition, we do not find evidence to support the proposition that a high degree of transparency is associated with higher output volatility.

The rest of this paper is organized as follows. The next section reviews the relevant empirical and theoretical literature. Section III provides a discussion of our survey dataset. The econometric analysis and the discussion of our results are contained in Section IV, and Section V assesses the robustness of those results.

\section{REVIEW OF THE LITERATURE}

The currently expanding theoretical literature on central bank transparency identifies various channels through which increased transparency may affect economic policy outcomes. Not all of these move in the same direction. And neither is there a universally accepted definition of central bank transparency. ${ }^{3}$ Various authors conceptualize transparency in different ways, focusing on preferences, models, knowledge about the shocks hitting the economy, the decisionmaking process, or the implementation of policy decisions. ${ }^{4}$ The models by Faust and Svensson (2000, 2001), Jensen (2000), Geraats (2001a), and Tarkka and Mayes (1999) all assume private information about the central bank's objectives/intentions. Transparency is modeled as the degree of asymmetric information about control

\footnotetext{
1 See Blinder (2000).

2 Some exceptions are the papers by Briault, Haldane, and King (1996) and Nolan and Schaling (1996). Their focus, however, is on accountability rather than on transparency, and these accountability measures involve only 14 countries.

3 Blinder et al. (2001) assess why, how, and what central banks do and should talk about. Winkler (2000) discusses issues related to the definition of transparency.

4 For example, see Geraats (2001a) for a classification.
} 
errors (Faust and Svensson, 2001, and Jensen, 2000) or (anticipated) economic shocks reflected in the policy instrument (Cukierman, 2000a,b, and Tarkka and Mayes, 1999).

In this paper we focus on the detail in which central banks publish forecasts, since this variable is of common interest both in theoretical models of transparency and in related policy debates. ${ }^{5}$ Furthermore, publication of forecasts may allow dissemination of information relating to the central bank's view of the world (economic models), stochastic shocks, or preferences.

For any form of central bank transparency to be relevant, some asymmetry of information in monetary policy must exist. Recent empirical work provides evidence suggesting central banks may possess superior information. Romer and Romer (2000), for example, show that if commercial forecasters had access to the Federal Reserve's inflation forecasts, they would generally find it optimal to adopt them, discarding their own forecasts. Peek, Rosengren, and Tootell $(1998,1999)$ also find that the Fed's forecasts benefit from an informational advantage over the public that assists the Fed in conducting monetary policy. Superior information here is a product of the Fed's supervisory function and includes information about non-publicly traded banks.

Increased central bank transparency may reduce uncertainty in financial markets. Studies employing various methodologies provide evidence that market participants react to the dissemination of macroeconomic information by the central bank. For example, Clare and Courtenay (2001) employ an event study methodology and use tick-by-tick exchange rate data from London International Financial Futures Exchange (LIFFE) futures contracts, finding that the publication of forecasts in the form of the Inflation Report has an information content for U.K. market participants. Kuttner and Posen (2000) examine how shifts in the Federal Reserve's and the Bank of Japan's degrees of transparency over time contributed to the reduction of exchange rate volatility. ${ }^{6}$ Additional arguments in favor of transparency in monetary policy include the insulation of monetary policy from political pressures, increased accountability, facilitation of fiscal and monetary policy coordination, and improved internal organization of central bank analysis. ${ }^{7}$

In Faust and Svensson (2001), a high degree of transparency in monetary policy is, in general, welfare improving. Increased transparency reduces the inflation bias, inflation variability, and employment variability. Faust and Svensson (2001) use a modified Barro-Gordon model. The central bank's employment target is not announced and varies over time according to an idiosyncratic component. Fluctuations in this component of the employment target tempt the central bank to deviate from an announced inflation target. The central bank controls inflation imperfectly and the inflation outcome has two components: the central bank's intentions and a control error. The central bank decides upon the extent to which it will reveal its knowledge of the control error to the public. By revealing the control error, the central bank renders its intentions for inflation observable and thereby enables the public to infer the central bank's employment goal. Thus the degree of central bank transparency increases as the central bank reveals a greater proportion of the observable component of the control error.

Analytically, Faust and Svensson (2001) distinguish among three different regimes of transparency. In the first (least transparent) regime, neither the employment objective nor the intentions of the central bank are observable by the public. In the second regime, with a high degree of transparency, the inflation intentions of the central bank become observable. Increased transparency in inflation intentions results in lower inflation because it increases the sensitivity of a central bank's reputation to its actions, making it more costly for the central bank to pursue a high-inflation policy. The third regime is one the authors classify as "extreme" transparency where both the employment goal and the intentions of the central bank are observable. The central bank's actions no longer convey additional information about the inflation bias, and its reputation is no longer affected by its actions. An inflationary bias reemerges resulting in higher inflation, inflation volatility, and unemployment variability. ${ }^{8}$

\footnotetext{
5 See, for example, Buiter (1999) and Issing (1999) for a lively debate about transparency and accountability among central bankers.

6 Other relevant studies include Dotsey (1987) and Haldane and Read (2000). Thornton (1999) provides evidence on whether the Fed controls the funds rate primarily through open market or "open mouth" operations.

7 These views were expressed by Josef Tošovsky, who was at that time Governor of the Czech National Bank. His views, and those of various other central bank governors, are contained in Mahadeva and Sterne (2000, pp. 186-205). For a discussion of policy-related arguments for transparency in monetary policy, see Blinder et al. (2001).

8 This result is consistent with the results of the more general model of policymaking by Morris and Shin (2001).
} 
Jensen (2000) adopts an informational structure similar to Faust and Svensson (2001), assuming that the output target is private information to the central bank and that the public's capacity to deduce it increases as the central bank publishes a greater percentage of the inflation control error. In contrast to Faust and Svensson (2001), who focus on the credibility effects of central bank actions in the future, Jensen (2000) uses a model with New Keynesian elements (staggered price-setting and monopolistic competition) and focuses on the marginal costs of inflation within the current period. More transparency increases the reputational costs of deviations from the inflation target and therefore increases its discipline and credibility.

The literature does not suggest that a high degree of transparency is unconditionally desirable. In Jensen's model, when central bank preferences are already public information, the credibility-enhancing effect of increased transparency becomes redundant. Furthermore, in the presence of a shock that requires counter-cyclical monetary policy, transparency becomes a straightjacket. Thus, the choice of the optimal degree of transparency is related to the trade-off between flexibility and credibility. A high degree of transparency is desirable for central banks with poor credibility but may be costly in terms of flexibility for high-credibility central banks.

Increased transparency may have the disadvantage of eliminating the central bank's strategic advantage, thereby reducing its capacity to stabilize the economy. "Cheap talk" and "optimal ambiguity" arguments are characteristic expressions of this view. ${ }^{9}$ Other papers focus less on the reputational aspects of transparency and more on the consequences of the central bank releasing information about stochastic shocks. In Cukierman's (2000b) one-period model, the central bank's private information is about an upcoming shock. He uses a neoclassical transmission mechanism, relying on an expectations-augmented Phillips curve (i.e., a standard Barro-Gordon model) and a model along the most recent neo-Keynesian lines that focuses on the interest rate instrument. He examines the welfare implications of different degrees of transparency in each model. Under a regime of "limited" transparency, the central bank reveals its information about the upcoming shock after the public's inflation expectations have been set; conversely, under "full" transparency this information is released before the public forms its expectations.

Different degrees of transparency in the neo- classical version of the model merely affect the variability of inflation and not its average level. This is because the public becomes aware of the supply shock, and thus the central bank loses its informational advantage and cannot generate inflation surprises to stabilize the economy. Expected social welfare, however, is always higher under a limited transparency regime compared with the full transparency regime. This is because, under full transparency, unexpected inflation is always zero and therefore the central bank cannot affect employment. This result holds under assumptions of both perfect and imperfect (noisy) central bank forecasts. Under perfect central bank forecasts, however, only the variance of the policy outcomes is affected, whereas under noisy forecasts the average policy outcomes are affected as well. ${ }^{10}$

In the neo-Keynesian model of Cukierman (2000b), society is indifferent between the two regimes provided that interest rate variability does not enter its loss function. When the social loss function includes interest rate variability, however, the limited-transparency regime is superior to the full-transparency regime. Because the model incorporates a typical instrument rule, premature forecast publication requires more nominal interest rate variability in order to stabilize the ex ante real rate and through it the output gap and inflation.

Geraats (2001a) uses a two-period Barro-Gordon model with a real-interest-rate transmission mechanism and focuses explicitly on the publication of central bank forecasts. The central bank has private information about both demand and supply shocks and does not publish its inflation target. More transparency in the first period allows the private sector to observe the first period's demand and supply shocks and make inferences about the central bank's inflation target. More transparency therefore makes the central bank's reputation more sensitive to its actions, so an "opaque" monetary policy regime is characterized by higher inflation in the first period. This is because the non-publication of the central bank's forecasts implies a reputation loss. Given the

9 For example, in the "cheap talk" model of Stein (1989), the central bank can generate inflation surprises. In the "optimal ambiguity" model of Cukierman and Meltzer (1986), imprecise control of the money supply allows the central bank to generate inflation surprises according to its time-varying preferences.

${ }^{10}$ Cukierman's (2000b) model does not include an explicit inflation bias, but our analysis shows that the results are similar when the model is extended to incorporate such a bias in the central bank's objective function. 
uncertainty about whether the central banker is "weak" or "strong" in its aversion to inflation, the public tends to interpret the non-publication as an indication that the central bank is "weak." Transparency reduces the variability of inflation, but the effect on output is ambiguous. More precisely, under transparency, supply shocks lead to greater variability of output, whereas demand shocks lead to less. The reason is that under opacity, the central bank has less flexibility to adjust the interest rate in response to shocks. So under opacity, supply shocks lead to more variability in inflation and less in output; thus the demand shocks are no longer completely offset, leading to greater variability of both inflation and output.

Tarkka and Mayes (1999) suggest that publishing the central bank's forecasts leads to better macroeconomic performance because the released information reduces the private sector's uncertainty about the central bank's intentions. The authors use a Barro-Gordon model and assume that the central bank does not publish its inflation target.

Our assessment of the literature points toward appropriate measures of transparency for empirical tests, possible implications for the macroeconomy, and channels through which transparency may affect inflation:

- Transparency is generally conceptualized as the publication of central bank forecasts, since this allows the public to observe the control error. ${ }^{11}$

- The literature identifies a number of channels by which transparency affects the macroeconomy. These are conditional on model choice and specification (e.g., neoclassical versus neo-Keynesian models, presence of inflation bias) and assumptions such as the initial degree of credibility enjoyed by the central bank, the precise degree of transparency, and whether the models are specified over one or more periods.

- The effects of increased monetary policy transparency in the existing theoretical models are associated with variables such as average inflation, output, inflation volatility, output volatility, and interest rate volatility. Thus the hypotheses we test in this paper are, in general, consistent with the theoretical propositions of the recent literature.

- A common element in the majority of the models is that increasing transparency makes the central bank's reputation more sensitive to its actions and therefore reduces the incentive to pursue inflationary policies. Transparency has less impact on the sensitivity of reputation to the actions of the central bank when its preferences are already known. Regardless of the different implications of increased transparency about social welfare in the above models, more transparency never results in higher inflation outcomes.

- Another common element is that the improvement in inflation performance may be offset by a reduction in the capacity of the central bank to stabilize the economy by surprising the private sector with a policy-induced demand shock.

\section{A NEW DATA SET ON CENTRAL BANKING INSTITUTIONS}

In measuring transparency of central bank forecasts, we seek to establish the scope and coverage of macro-forecasts published by central banks. Data are taken from a survey of central banks contained in FJMRS. ${ }^{12}$ They provide estimates of many transparency characteristics. We focus on central bank publication and explanation of macroeconomic forecasts, since this emphasis is closest to that of both theoretical and policy-oriented work on transparency in monetary policy.

The great majority of central banks in our sample publish some form of forward-looking analysis79 percent of the 94 covered in the FJRMS survey. ${ }^{13}$ Forward-looking analysis may, of course, take many forms, some of which may help to guide expectations more than others. For some central banks, the publication of a money target is in itself a form of forward-looking analysis, since such targets are often more benchmarks rather than rules, and other forecasts must underpin the target. Other central banks have attempted to guide inflation expectations by presenting forecasts of a number of variables in

\footnotetext{
11 An exception in the recent theoretical literature is Cukierman (2000a), who focuses on the economic model and the operational objectives of the central bank rather than central bank forecasts and votes.

12 The characteristics covered in the FJMRS survey include numerical measures of how policy decisions are explained and the quantity of current analysis, research, and speeches provided by the central bank. They also assess and provide scores for various aspects of accountability, independence, and target setting, each of which may contribute to transparency and clarity in the monetary framework.

${ }^{13}$ A total of 82 of these observations are included in our estimates. The other 12 are excluded because other data do not match up with them
} 


\section{Table 1}

Measure of Explanations of Forecasts and Forward-Looking Analysis: Questions and Distributions of Responses

\begin{tabular}{|c|c|c|c|c|c|}
\hline Questions & $\begin{array}{l}\text { Categories of answers, } \\
\text { distribution of results }\end{array}$ & All & Industrial & Transitional & Developing \\
\hline \multirow{4}{*}{$\begin{array}{l}\text { Form of publication } \\
\text { of forecasts }\end{array}$} & Words and numbers & 35 & 16 & 5 & 14 \\
\hline & Either words or numbers & 25 & 8 & 6 & 11 \\
\hline & Unspecified & 13 & 0 & 4 & 9 \\
\hline & None & 21 & 4 & 7 & 10 \\
\hline \multirow{4}{*}{$\begin{array}{l}\text { Forward-looking analysis } \\
\text { in standard bulletins } \\
\text { and reports }\end{array}$} & More than annually & 39 & 18 & 7 & 14 \\
\hline & At least annually & 24 & 4 & 4 & 16 \\
\hline & Unspecified & 10 & 2 & 4 & 4 \\
\hline & Otherwise & 21 & 4 & 7 & 10 \\
\hline \multirow{3}{*}{$\begin{array}{l}\text { Discussion of past } \\
\text { forecast errors }\end{array}$} & Yes & 21 & 8 & 3 & 10 \\
\hline & Sometimes & 9 & 7 & 2 & 0 \\
\hline & No & 64 & 13 & 17 & 34 \\
\hline \multirow{3}{*}{$\begin{array}{l}\text { Risks to forecast } \\
\text { published }\end{array}$} & Words and numbers & 9 & 7 & 2 & 0 \\
\hline & Either words or numbers & 23 & 9 & 4 & 10 \\
\hline & None & 62 & 12 & 16 & 34 \\
\hline
\end{tabular}

considerable detail including, for example, a discussion of risks.

The questions in the survey ask not only whether the central bank provides forward-looking analysis. They also consider the quality, scope, and frequency of forecasts and the extent to which forecast errors are monitored and publicly discussed. The exact wording of the questions, along with the motivation behind them, is provided below, with the distribution of the results for each question shown in Table 1. The questions are:

- What is the form of publication of forecasts? Is it in words only, or is it also presented formally in terms of numbers? ${ }^{14}$

Motivation: The "bottom line" of a forecast is usually presented in a numerical or graphical format, which may help to influence expectations and discipline policy, since the forecast may then be directly compared with a target, and subsequently outcomes may be compared with the forecast. The analysis underpinning the forecast may, however, be more important than the precise number, since the accuracy of numerical forecasts may sometimes be attributable to luck as well as judgment. The questionnaire distinguishes between those central banks that publish forecasts: (i) using both words and numbers, (ii) using either words or numbers, and (iii) using neither.

- With what frequency does the central bank publish forward-looking analysis in standard bulletins and reports?

Motivation: Published annual targets for money and inflation may help to guide expectations, but they only do so over a particular horizon. Forecasts published more frequently will guide/anchor expectations and may discipline policy over different forecast horizons.

- Are risks to the forecast published; if so, in what form?

Motivation: A number of central banks use their forecast as a vehicle for highlighting the relative likelihood of various outcomes, rather than to focus on a particular number. The argument for publishing risks to a forecast is that a forecast that rests on a single number for each time period may be accurate for spurious reasons. An assessment of risks can convey a more accurate representation of the forecasters' subjective assessment of monetary conditions. As with the first question, the quality of risk assessment is judged

\footnotetext{
${ }^{14}$ Graphs are treated as identical to numbers in this analysis.
} 
according to whether both numbers and words are used.

- Is there a discussion of past forecast error; if so, is this a standard feature of discussion?

Motivation: Attempts to build credibility may rest on becoming more open about the capacity of the central bank (and other institutions) to forecast accurately. An open assessment of forecast errors may also reinforce the quality of future forecasts.

\section{Data Reliability}

The FJMRS survey data are the most comprehensive description available of central bank efforts to explain policy. The questions are worded objectively and cover a number of aspects of forecasting whose publication could enhance transparency to varying degrees, yet there are a number of reasons that might suggest caution in interpreting and using the data. We assess the implications of each in turn.

First, there could be a problem of sample selection bias to the extent that only the "best performers" respond. We are confident that the FJRMS survey is largely immune to this problem because of the very high response rate. Of 114 questionnaires, 94 were completed, and the survey covers over 95 percent of world gross domestic product (GDP). Furthermore, as the discussion of forecasts was only one facet of a broad survey, it is less likely that central banks were deterred by this particular part of the questionnaire.

Second, there could be problems with the subjective nature of the responses. For example, the distinction between publishing regular targets and forecasts may become blurred in some cases. Some respondents may have interpreted publishing an intermediate money target as providing forwardlooking analysis. Such a target, after all, must be based upon output and inflation projections. Other countries, however, interpreted the publication of an intermediate target as distinct from publishing a forecast. This potential subjectivity bias may not be serious, however, since the questionnaire asked about the nature of publication, its frequency, and the discussion of risks and forecast errors.

A third problem is that it may be relatively easy to change some transparency characteristics. Some of the transparency measures in the survey have been implemented only recently, and so they may not have had an impact on inflation in the sample. If the impact of these measures represents a signifi- cant change in central bank behavior, the effect may also take some time to influence inflation expectations. We consider this problem in the discussion of the robustness of our empirical results.

\section{EMPIRICAL METHODS AND RESULTS}

As noted above, theoretical work on transparency has generated a number of different propositions about the effect of publishing central bank forecasts. In order to evaluate these alternative models, in this section we provide empirical tests of the effect of transparency on inflation and on the volatility of output, using a cross-section of 87 countries over the period 1995-99. Our results show that there is a statistically significant negative correlation between transparency and inflation and, in particular, in countries with flexible exchange rate regimes. At the same time, there is no evidence of a cost of transparency in terms of increased output volatility.

\section{Constructing an Index for Transparency of Forecasts}

The FJMRS data set provides four separate indicators that can be used to assess the detail in which a central bank publishes its inflation forecasts. These include the frequency with which forecasts are published and whether past forecast errors and risks to the forecast are discussed in publications. These indicators are highly correlated, implying that any regression that included each would exhibit multicollinearity. This factor argues in favor of aggregating the four to produce a composite measure of transparency.

Rather than creating an aggregate measure by simply taking the average of the different transparency measures in the FJMRS data set, we considered to what extent the FJMRS indicators can be arranged to form a Guttman scale. Its major advantage is that, unlike an average of several variables, a Guttman scale constructed from several indicators does not result in a loss of information through aggregation. A Guttman scale is constructed by arranging binary variables in a sequence such that a positive value for one indicator implies a positive value for all previous variables in the sequence. To construct a Guttman scale for transparency, we have ordered our variables according to the decision tree in Figure 1. Although a few of the central banks in our sample do not fit this pattern (for example, they discuss risks to their forecast but not past forecast 


\section{Figure 1}

\section{A Guttman Scale of Transparency in Forecasting}

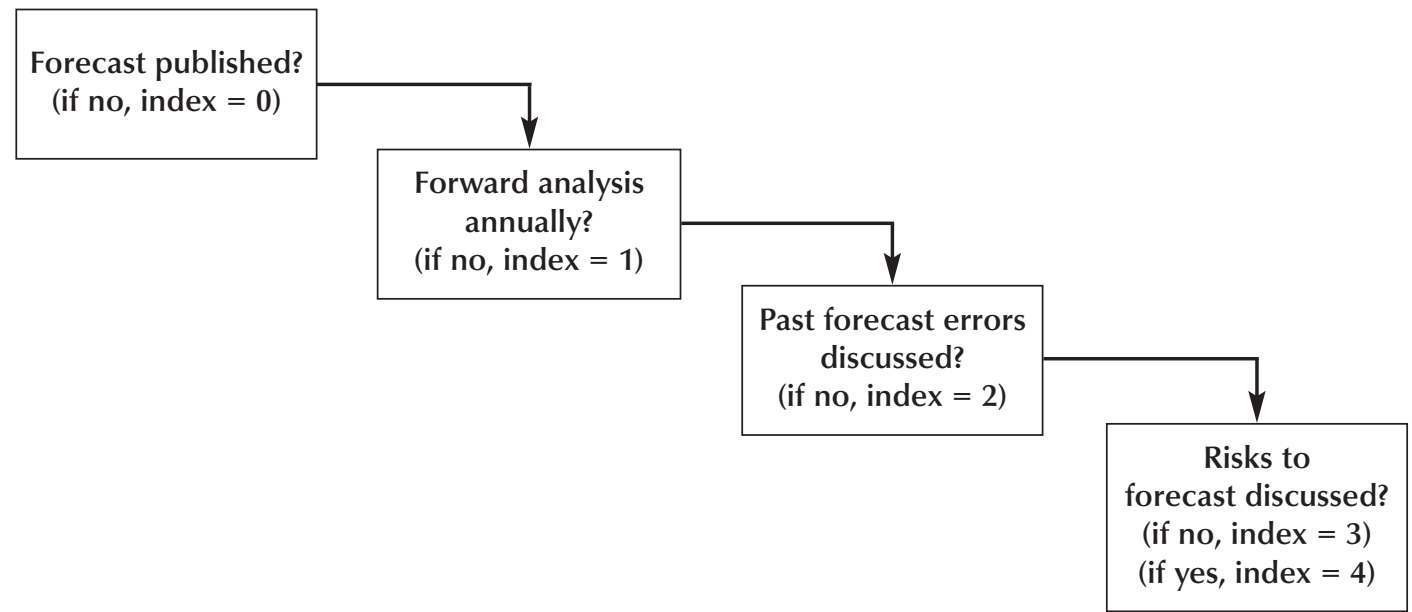

errors), the vast majority did. A common criterion for judging whether data can be ordered in a Guttman scale is if the "coefficient of reproducibility," defined as the number of errors/total responses, is less than 0.10. ("Errors" are cases where ordering according to a Guttman scale results in a false prediction for a response.) Our transparency data set easily satisfies this criterion, with a ratio of errors to total responses of $0.08 .^{15}$

The advantage of Guttman scaling is that, based on the aggregate index, one can determine exactly how a central bank scores on each of the four separate sub-indicators. So, for example, a score of 2 on our transparency index implies that a central bank publishes forecasts and that it does so on at least an annual basis, but it does not discuss either past forecast errors or risks to the current forecast. ${ }^{16}$ In contrast, if we took the simple average of the four indicators, then a score of 2 could imply a positive response on any two of the four sub-indicators. Furthermore, we later show that our results are robust to the use of either a Guttman scale or the simple average of our four sub-indicators of transparency in forecasting. The distribution of the Guttman scores is as follows: Of the 82 countries, 25 have a Guttman score of $0 ; 8$ have a score of $1 ; 24$ have a score of 2 ; 6 have a score of 3; and 19 have a score of 4 .

\section{Transparency and Inflation}

As a first step toward investigating the effect of transparency in forecasting in monetary policy, we examined whether our index is negatively correlated with average inflation across our 87-country sample. Because the FJMRS data set examined transparency at one specific point in time (1998), we are limited to tests that consider only cross-country variation in inflation, rather than variation over time. Given that many reforms to increase central bank transparency are quite recent, we also chose to use a brief period for calculating average inflation (1995-99). This is based on consumer price index (CPI) data from the International Monetary Fund's International Financial Statistics. As discussed later, our results are nonetheless robust to using different time periods and to running regressions based on data from individual years.

Table 2 presents pairwise correlations between levels of transparency and average inflation. We use both our overall index and individual measures from the FJMRS data set. There is a significant negative correlation between all of these indicators and both the level and the variability of inflation, and this correlation is significant for the Guttman index in both cases.

As a next step, we examined whether this relationship holds when controlling for other deter-

\footnotetext{
${ }^{15}$ Alternative orderings, such as scaling in the following order of (i) forecasting, (ii) forward analysis, (iii) risks to forecast, (iv) past forecast errors, generate virtually identical results for the 82-observation sample that we use in our regression.

${ }^{16}$ This highlights the importance of having the overall data set closely approximate a perfect Guttman scale, in order to be able to make this inference.
} 


\section{Table 2}

\section{Transparency and Inflation: Pairwise Correlations}

\begin{tabular}{ll} 
& Log inflation \\
\hline Guttman scale of transparency & $-0.37(p<0.01)$ \\
Publication? & $-0.29(p=0.01)$ \\
Forward analysis at least annually? & $-0.15(p=0.15)$ \\
Past forecast errors discussed? & $-0.21(p=0.05)$ \\
Risks to forecast considered? & $-0.28(p=0.01)$
\end{tabular}

Number of observations

87

minants of average inflation. ${ }^{17}$ To do this we followed existing cross-country empirical literature on inflation including Campillo and Miron (1996), Lane (1997), Bleaney (1999), Romer (1993), and Ghosh, Gulde, and Ostry (1995). First, we included the log of real GDP per capita, based on the possibility that lower-income countries may rely more heavily on the inflation tax to finance government expenditures. Second, we included a measure of openness, ${ }^{18}$ following Romer (1993) and Lane (1997) who argue that incentives for policymakers to generate "surprise" inflation are weaker in more open economies. We also included a measure of political instability as a control variable, based on the prediction from a number of different political economy models that a high frequency of government turnover may shorten the time horizons of politicians, prompting them to adopt more inflationary macroeconomic policies. ${ }^{19}$ Finally, we added a dummy variable to control for a country's exchange rate regime (fixed $=1$ ). ${ }^{20}$ This follows the theoretical arguments that emphasize how pegging can serve as a commitment device. It also follows empirical findings of Ghosh, Gulde, and Ostry (1995), Bleaney (1999), and others who show that there is a clear negative correlation between exchange rate pegs and average inflation.

Table 3 reports the results of four cross-country regressions. Regression (1) includes each of our control variables in addition to our Guttman scale for transparency in forecasting. The coefficient on the scale is negative and highly significant. Our second regression adds an interaction term, which allows the effect of transparency to vary between countries with fixed exchange rates and those with flexible exchange rate regimes. This tests our hypotheses about transparency in forecasting with greater precision because arguments in favor of publishing inflation forecasts apply, above all, to economies with floating exchange rates where the monetary authorities have greater control over the domestic money supply. In small open economies with a fully credible fixed exchange rate regime and with full convertibility, publishing forecasts should have no effect on average inflation since the central bank has little or no control over domestic interest rates or the money supply. Following Canavan and Tommasi (1997) and Herrendorf (1999), exchange rate pegs can be seen as an alternative strategy for establishing transparency, since they provide the public with an easily observable indicator over which the government has direct control.

The results of regression (2) in Table 3 correspond to those predicted in theory. In countries with floating exchange rates, transparency in forecasting is negatively correlated with average inflation. The coefficient on our transparency index is highly significant and becomes more negative when compared with the result from regression (1). ${ }^{21}$ The significance is accounted for by a high-point estimate of the effect of transparency in inflation coupled with relatively wide error bands. In a country with a floating exchange rate that began with an inflation rate of 12 percent per annum, we estimate that a decision by the central bank to begin publishing regular inflation forecasts (a move on the index from 0 to 2) would lead to a reduction in inflation of between 1.8 percent and 7 percent per annum (the 95 percent confidence interval). In contrast, in countries with fixed exchange rates, transparency in forecasting has less effect on inflation. According to our estimates, the effect of a similar increase in transparency in forecasting in a fixed exchange rate country would be much smaller (reducing inflation from 12 percent to 11.8 percent per annum).

We also investigated whether the effect of transparency in forecasting on inflation might depend

\footnotetext{
${ }^{17}$ We restrict our attention to average inflation here because existing empirical work focuses on this variable.

${ }^{18}$ We define openness as $(x+m) / G D P$, where $x$ and $m$ stand for exports and imports, respectively.

${ }^{19}$ Drawn from a database created by Beck et al. (1999), this variable measures the percentage of key decisionmakers (executive, legislative majority[ies], coalition members) that change in a given year.

20 Based on the classifications in the IMF's Annual Report on Exchange Arrangements and Exchange Restrictions.

21 The results are very simple from a regression that excludes countries with pegged exchange rates.
} 


\section{Table 3}

\section{Transparency in Forecasting and Average Inflation}

Dependent variable: log inflation

\begin{tabular}{lccc}
\hline Log GDP per capita & $-0.47^{* *}(0.07)$ & $-0.45^{* * *}(0.07)$ & $-0.50^{* * *}(0.066)$ \\
Openness & $-0.001(0.002)$ & $-0.001(0.002)$ & $-0.002(0.002)$ \\
Political instability & $1.13^{*}(0.63)$ & $0.97(0.64)$ & $1.07^{*}(0.63)$ \\
Exchange rate peg $($ peg $=1)$ & $-0.47^{* *}(0.23)$ & $-0.95^{* *}(0.43)$ & $-0.74^{*}(0.40)$ \\
Transparency in forecasting index & $-0.16^{* *}(0.07)$ & $-0.26^{* * *}(0.09)$ & $0.01(0.10)$ \\
Peg $\times$ transparency & & $0.25^{*}(0.13)$ & $-0.15^{*}(0.08)$ \\
Inflation target $\times$ transparency & & & $-0.24^{* *}(0.01)$ \\
Money target $\times$ transparency & & $6.11^{* * *}(0.51)$ & $6.40^{* * *}(0.55)$ \\
Constant & $6.04^{* * *}(0.54)$ & 0.54 & 82 \\
\hline $\mathrm{R}^{2}$ & 0.52 & & 0.52 \\
$\mathrm{~N}$ & 82 & & 82
\end{tabular}

NOTE: Heteroskedastic-consistent standard errors are in parentheses; ${ }^{* *},{ }^{* *}$, and $*$ indicate significance at the 1,5 , and 10 percent levels, respectively.

on whether countries are inflation targeters or whether they target monetary aggregates. A number of authors have defined transparency as a key ingredient of inflation targeting (e.g., Mishkin, 2000), while some have gone further by arguing that transparency is a prerequisite to inflation targeting (Masson, Savastano, and Sharma, 1997). The latter argument would suggest that transparency should have a greater impact on the credibility of monetary policy when adopted in conjunction with the use of an inflation target. In regression (3) in Table 3, we include two multiplicative dummy variables representing transparency in countries whose frameworks are based on inflation targets and money targets. We first construct two variables, inflation target and money target, each of which is a binary variable compiled from several different indicators in the FJMRS data set. ${ }^{22}$ These two variables are then multiplied by the Guttman scale such that the inflation (money) target multiplicative dummy is equal to the value of the Guttman scale when the country's framework is based more upon an inflation (money) target and is equal to zero otherwise. The results of regression (3) suggest that the effect of transparency on inflation may be stronger for money-targeting frameworks, but tests reveal that the difference between the coefficients is insignificant. In unreported results, we find that when the binary dummy variables, inflation target and money target, are included separately, neither is significant.

Our estimates of the effects of our control variables on inflation are consistent with previous studies. Income per capita is negatively correlated with inflation, while political instability tends to be associated with higher inflation. As in previous studies, there is a very large and very significant negative correlation between exchange rate pegs and inflation. One finding that may appear surprising is the result that greater openness of an economy to trade is not associated with lower inflation. Earlier studies by both Romer (1993) and Lane (1997) using data covering the 1970s and 1980s found evidence of a negative openness-inflation correlation. More recently Bleaney (1999) has reproduced earlier findings with regard to the 1970s and 1980s, while also concluding that there is no significant correlation between openness and inflation in data from the 1990s. Given that our data cover the period 1995-99, our results are consistent with those obtained by Bleaney. We also investigated whether these results

\footnotetext{
22 The questions ask central banks (i) to classify their regime, (ii) to report if an explicit target was published for each variable, (iii) to rank objectives in practice, and (iv) to indicate which variable prevails in policy conflicts. Each country was allocated a score for each of the following: exchange rate, money and inflation focus, and discretion. The maximum of these scores was classified as the "targeted" variable. This definition is broader than that used in other papers (e.g., Mishkin and Schmidt-Hebbel, 2000)
} 


\section{Table 4}

Transparency and Output Volatility: Pairwise Correlations

\begin{tabular}{lcc} 
& $\begin{array}{c}\text { Standard deviation } \\
\text { annual GDP growth (p value) }\end{array}$ & $\begin{array}{c}\text { Standard deviation } \\
\text { quarterly GDP growth (p value) }\end{array}$ \\
\hline Guttman scale of transparency & $-0.08(0.47)$ & $-0.29(0.13)$ \\
Publication? & $0.06(0.59)$ & $-0.10(0.60)$ \\
Forward analysis at least annually? & $0.02(0.86)$ & $-0.25(0.19)$ \\
Past forecast errors discussed? & $-0.22(0.06)$ & $-0.20(0.29)$ \\
Risks to forecast considered? & $0.09(0.43)$ & $0.16(0.40)$ \\
Number of observations & 76 & 29 \\
\hline
\end{tabular}

\section{Table 5}

Transparency and Output Volatility: Controlling for Terms of Trade Variability

\begin{tabular}{lcc} 
Dependent variable & $\begin{array}{c}\text { Standard deviation } \\
\text { annual GDP growth }\end{array}$ & $\begin{array}{c}\text { Standard deviation } \\
\text { quarterly GDP growth }\end{array}$ \\
\hline Guttman scale of transparency & $-0.03(0.12)$ & $-0.005(0.004)$ \\
Standard deviation terms of trade shocks & $0.53^{* * *}(0.14)$ & $0.23(0.29)$
\end{tabular}

Number of observations

71

28

NOTE: Heteroskedastic-consistent standard errors are in parentheses; ${ }^{* * *},{ }^{* *}$, and ${ }^{*}$ indicate significance at the 1,5 , and 10 percent levels, respectively.

with regard to openness were attributable to outliers with very high levels of openness, but our results rejected this possibility.

\section{Transparency and Output Volatility}

In addition to making predictions about the effect of transparency on average inflation, models of transparency in monetary policy also produce comparative statistics about volatility of output. 23 As noted, one's prediction here depends heavily on underlying assumptions. Our empirical investigation of the effect of transparency on output volatility is limited by the lack of obvious controls to be used in estimating cross-country differences in output volatility. To construct measures of output volatility (based on the standard deviation of GDP growth), annual data were available for our entire sample (1993-99), while quarterly GDP data were available for 30 of our sample countries (also 1993-99).

Table 4 reports the results of pairwise correlations, using both the Guttman scale for transparency and the individual indicators from the FJMRS data set. There are several extreme outliers in our output volatility data, and in order to obtain more robust results we have excluded these countries from the correlations reported in the table. ${ }^{24}$ The results show that the correlation between transparency and output volatility is often negative, especially in the sample using quarterly data, but in only one case is a correlation significant at conventional levels. While this evidence certainly does not suffice to demonstrate that publishing inflation forecasts reduces output volatility, it does appear to be fairly strong prima facie evidence against claims that

\footnotetext{
${ }^{23}$ We also tested for the effects of transparency on the volatility of inflation, and our tentative results showed no significant positive or negative impact.

24 In the sample based on annual data, Kuwait and the Kyrgyz Republic were outliers in terms of having very high standard deviations of GDP growth, while in the quarterly data Turkey was the only severe outlier We defined a "severe" outlier, $x$, using the following formula where "pctile" refers to the percentiles of the entire sample: $x<25$ pctile 3 (75pctile -25 pctile) or $x>75$ pctile +3 (75pctile -25 pctile).
} 
increasing transparency increases output volatility. Results obtained before outliers were excluded were also consistent with this finding. ${ }^{25}$

We also estimated several ordinary least squares (OLS) regressions of output volatility on the Guttman scale of transparency, controlling for the variance of terms of trade shocks. ${ }^{26}$ The results, reported in Table 5, show no significant effect of increased transparency on output volatility.

\section{INTERPRETING THE ROBUSTNESS OF OUR RESULTS}

The effort required for a central bank to publish detailed forecasts may not appear to be particularly arduous relative to the benefits of securing lower inflation. Why, then, do many more central banks not introduce detailed forecasts? 27 We base our detailed discussion of the robustness of our results on five complementary explanations of this empirical conundrum:

- The result (that greater transparency in forecasting leads to lower inflation) is valid and could be exploited by more central banks than at present, but some central banks have not yet completed the transition to greater transparency.

- The result is valid overall but may not be true of all frameworks.

- The result is valid, but there may be offsetting costs to transparency, which deter some central banks from introducing it.

- The results may be overstated or invalid because of endogeneity and reverse causality.

- There may be other statistical biases.

Econometric techniques are necessary but insufficient for judging the robustness of our results. In this section we also include a detailed discussion of how such tests relate to the theory and practice of monetary frameworks.

\section{A Transition to Greater Global Transparency in Monetary Policy?}

One possible reason why only a relatively small number of central banks publish detailed forecasts may be that policymakers have not yet fully acted upon the evidence that transparency can contribute to lower inflation. The theoretical and empirical evidence on the effects of transparency is relatively new. Goodfriend's (1986) landmark paper was among the first to discuss the costs and benefits of secrecy in monetary policy, in the context of the Merrill vs. FOMC case. ${ }^{28}$ His paper was framed by questions relating to how central banks might respond to increasing evidence of the importance of expectations in economic decisionmaking. The theoretical literature began to increase rapidly only at the end of the 1990s, and our paper is among the first to provide cross-country empirical evidence using macroeconomic data. Similarly, the practical precedents of frameworks in which published forecasts contributed significantly in building credibility have emerged only in the 1990s. ${ }^{29}$

Framework designers have not always been quick to adjust their frameworks quickly in response to new framework innovations, ${ }^{30}$ yet recent developments in global framework design suggest that central banks are on a transition path toward much higher average levels of transparency. Even since FJMRS constructed their data, several countries have markedly increased the information about their forecasts. ${ }^{31}$ And the rapid global proliferation of explicit money and inflation targets in the 1990s is, according to Mahadeva and Sterne (2001), part of a global trend whereby disinflating countries use targets more as a forecasting device than as a policy rule.

${ }^{25}$ Before exclusion of outliers, all correlations were negative and seven of ten were significant at conventional levels.

${ }^{26}$ The variable was based on an indicator from the World Bank's World Development Indicators. We then calculated this effect as a share of GDP and took the standard deviation of this indicator over the period 1992-97.

${ }^{27}$ In the FJMRS survey, only three central banks (Norway, Sweden, and the United Kingdom) satisfy every criterion by which the authors judged the detail in which central banks explain forecasts.

${ }^{28}$ One of the Fed's arguments for resisting greater transparency, that it was difficult in the early 1980 s to provide information evenly to all market participants, has been eroded over time by advances in information technology.

29 The discussion of central bank governors in Mahadeva and Sterne (2000, pp. 182-205) illustrates that inflation-targeting countries have made transparency a key aspect of their framework. The Bundesbank has, according to Posen (2000), a long history of explaining its policies well, yet its independence is more widely perceived as contributing more strongly to its credibility.

${ }^{30}$ For example, if regimes are classified according to money targeting, exchange rate targeting, inflation targeting, and discretion, then only three countries (Australia, the United Kingdom, and Uruguay) have changed their regime as much as four times since the breakdown of the Bretton Woods agreement.

31 Brazil, Chile, South Africa, and Thailand each now publish fan charts for inflation and provide explicit discussion of risks to inflation forecasts in regular inflation reports. 


\section{Figure 2}

\section{Results of Recursive Estimation}

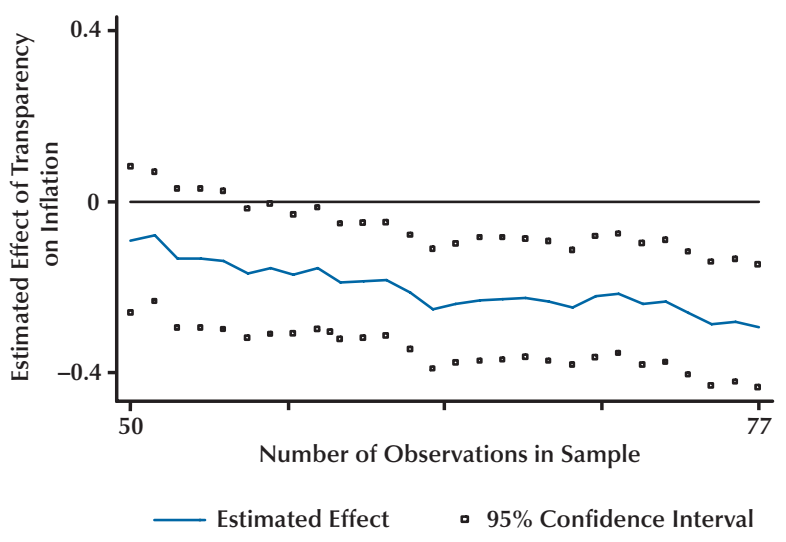

\section{Transparency May Have Significantly Different Effects on Inflation Across Frameworks}

Our discussion suggests that more explanation of policy does not significantly reduce inflation under all circumstances. Moreover, our point estimates of the overall effect, though large, were surrounded by relatively wide error bands, suggesting that there are a number of frameworks that are exceptions to the overall result. The governance structure of the central bank may affect the willingness of the central bank to publish forecasts. In some central banks, senior policymakers are responsible for the published forecast; in others, the central bank's staff are the sole authors. ${ }^{32}$ Such differential arrangements may affect the perceptions of policymakers and the public alike regarding the closeness of the link between published forecasts and policy decisions, and this in turn may affect the transmission channels between transparency and inflation outcomes. To the extent that transparency operates by enhancing credibility, as is predicted by a number of the models we have discussed, the effect of transparency on inflation may be smaller when credibility has been secured by actions rather than words. This applies to exchange rate targeters (see results noted previously) and may also apply to countries with low inflation. 33

Given that our sample includes countries both with very low and very high average rates of inflation, we examine the extent to which our results are stable when we exclude high-inflation countries from the sample. As a first step, we used a standard procedure to determine whether the coefficient on the Guttman scale was influenced by outliers. This resulted in the exclusion of five observations, after which the coefficient on the Guttman scale remained significant. ${ }^{34}$ We then used a recursive estimation procedure to examine how our results changed as we progressively excluded high-inflation observations from the remaining sample. This was an iterative procedure which involved the following: (i) estimating regression (2) in Table 3 using a sample of the 50 countries with the lowest average rates of inflation, (ii) adding the observation with the next highest rate of inflation, and (iii) reestimating the regression and then repeating the process until we reached maximum sample size. Figure 2 plots the estimated coefficient on the Guttman scale, together with bounds for the 95 percent confidence interval according to sample size. The coefficient becomes progressively more negative as we include highinflation countries in the sample, suggesting that the estimated anti-inflationary effect of publishing a forecast in our Table 3 regressions may be somewhat inflated by the inclusion of high-inflation countries.

\section{Costs to Publishing Forecasts}

There may be political and economic costs associated with a central bank publishing forecasts, and these may offset the benefits of potential reductions in inflation. To the extent that fiscal policy may in some circumstances be the root of high inflation, detailed forecasts are likely to pinpoint the source of the problem and could, in some cases, lead to tensions between the central bank and the government. Transparency may, in such circumstances, also be proxying for a degree of central bank inde-

32 Kohn (2001) and Svensson (2001) include discussions on ownership of the forecast in their respective reports.

33 A related issue is the optimal degree of transparency. It is conceivable that there exist circumstances when increased transparency might lead to a deterioration in welfare or an increase in inflation. Telling the public about a likely financial or exchange rate crisis might precipitate the crisis. And many central banks have developed well-resourced press offices to manage the clarity of published information.

34 The countries excluded were Bahrain, Indonesia, Mauritius, Turkey, and Russia. We tested for outliers based on the dfbeta statistic, which measures the impact of an individual observation on a specific coefficient. Following standard practice, we excluded observations for which the absolute value of the dfbeta statistic was greater than

$$
(2 / \sqrt{n})
$$

where $n$ is the number of observations. The coefficient on the Guttman scale was $-0.29(0.08), p<0.01$, after five outliers were eliminated (based on regression (2)). 
pendence that may be very difficult to measure in conventional surveys. ${ }^{35}$

There may also be economic costs to introducing transparency that prevent central banks from publishing forecasts. The discussion of theoretical literature pointed to circumstances in which greater transparency may be associated with higher volatility in inflation and output. Where there is a risk of a banking or exchange rate crisis, for example, it is questionable whether or not a central bank should highlight such an issue by publishing forecasts. Cross-country evidence presented in Chortareas, Stasavage, and Sterne (2002) indicates that increased transparency may reduce the costs of disinflation in a sample of mainly industrialized economies.

\section{Endogeneity and Reverse Causality?}

There is a possibility that the results may be affected by reverse causality whereby low inflation may lead to greater transparency as well as being caused by it. Similarly there may exist endogeneity caused by cross-country differences in institutional circumstances, or macroeconomic conditions may imply systematic variation in transparency and inflation. In this section we seek to address these issues that have potentially serious implications for bias in our results.

Could it be the case that low inflation dissolves a central bank's preference for secrecy? Geraats (2001a) models the effect of transparency on the utility of both strong and weak central banks. Strong central banks are defined as having lower (unpublished) inflation targets than weak ones. She considers two alternative scenarios that shed light on the issue of endogeneity. In the first, transparency is exogenous, being imposed by the public. Weak central banks prefer secrecy since it affords them an opportunity to conduct stabilization policies with a lower probability of their preferences for relatively high inflation being revealed. In the case of transparency being an endogenous choice of the central bank, however, weak central banks also choose greater transparency. They overcome an inclination toward secrecy because they appreciate that secrecy will itself be interpreted by rational agents as a sign of weakness. ${ }^{36}$

We attempt to assess empirically the extent of any endogeneity. First, we can demonstrate that although transparency is positively correlated with other measurable characteristics of a country's economic, legal, and political environment, our results remain robust even when we control for the fact that transparency might be endogenous to these other factors. The second column in Table 6 shows simple correlation coefficients between our Guttman scale of transparency and other variables to which it might arguably be endogenous. These include measures of development (per capita GDP, OECD membership), other features of monetary policy (a focus on inflation objectives, legal central bank independence, quality of central bank analysis ${ }^{37}$ ), and measures for the political environment (democracy, political instability, political polarization, type of legal system ${ }^{38}$ ). As one might expect, transparency is positively correlated with a number of these variables, but in no case is the correlation high enough to suggest that transparency is perfectly correlated with another variable. Two of these variables, per capita GDP and political instability, are already included in our Table 3 regressions. As a next step, we reestimated regression (2) from Table 3 while adding one of the variables that may affect transparency. We repeated this procedure for each variable. In every single case, the coefficient on the Guttman scale remains negative, significant, and of roughly the same magnitude as in the original regression. The Guttman scale coefficient also remained significant when we included all variables in Table 6 simultaneously.

Although we can demonstrate that our transparency index is not merely proxying for levels of income or the level of democracy, it remains possible that our index may, to some extent, be influenced by some other political or economic variable $x$ which may be difficult to measure directly. It may be possible to investigate this indirectly, though. If this unmeasurable variable $x$ involves some broad change in the economic or political conditions that

${ }^{35}$ Fry (1998) questions the extent to which survey measures are capable of fully capturing central bank independence.

${ }^{36}$ Geraats qualifies this channel in her paper and provides possible reasons why, in spite of her results under endogenous choice of transparency, not all central banks are transparent. Furthermore, in Geraats (2001b) the author shows that the desirability of transparency depends critically on the institutional framework. In this model, when the central bank has limited independence, less transparency reduces the government's information about the economy, which discourages it from overriding the central bank

${ }^{37}$ The FJMRS study collected data on the extent to which central banks conduct detailed analysis of inflation expectations (based on market information) and on the sophistication of the models used to generate forecasts.

${ }^{38}$ The type of legal system is a dummy variable distinguishing whether countries have a common legal system. Data are taken from La Porta et al. (1998). 


\section{Table 6}

\section{Correlation of Transparency to Economic, Political, and Legal Variables}

\begin{tabular}{lccc} 
& $\begin{array}{c}\text { Correlation } \\
\text { with Guttman }\end{array}$ & $\begin{array}{c}\text { Coefficient on Guttman } \\
\text { after inclusion }\end{array}$ & $\begin{array}{c}\text { Number of } \\
\text { observations }\end{array}$ \\
\hline Democracy & 0.23 & $-0.34(0.10)$ & 64 \\
GDP per capita & 0.34 & $-0.26(0.09)$ & 82 \\
OECD member & 0.39 & $-0.21(0.09)$ & 82 \\
Inflation target & 0.17 & $-0.26(0.10)$ & 82 \\
Central bank independence (FRJMS) & 0.32 & $-0.28(0.10)$ & 82 \\
Central bank independence (Cukierman $\left.{ }^{\ddagger}\right)$ & -0.10 & $-0.39(0.12)$ & 47 \\
Type of legal system & 0.15 & $-0.26(0.10)$ & 82 \\
Quality of CB analysis & 0.44 & $-0.32(0.09)$ & 82 \\
Political instability & 0.07 & $-0.26(0.09)$ & 82 \\
Political polarization & 0.02 & $-0.24(0.09)$ & 82
\end{tabular}

NOTE: "Democracy" from the Polity III data set; "inflation target," "central bank independence," and "quality of analysis" from the FJMRS data set; "political instability" and "polarization" from Beck et al. (1999). Heteroskedastic-consistent standard errors are in parentheses; ${ }^{* * *}, * *$, and ${ }^{*}$ indicate significance at the 1, 5, and 10 percent levels, respectively.

tEach coefficient may be compared to $\mathbf{- 0 . 2 6}$, the result from regression (3) in Table 3.

‡Cukierman's central bank independence measure for 1980-89. A number of smaller countries in Cukierman's data set were not included in the FJMRS survey.

\section{Table 7}

\section{Endogeneity of Transparency to Broader Policy Measures}

\begin{tabular}{lccc} 
& $\begin{array}{c}\text { Correlation } \\
\text { with Guttman }\end{array}$ & $\begin{array}{c}\text { Coefficient on Guttman } \\
\text { after inclusion }\end{array}$ & $\begin{array}{c}\text { Number of } \\
\text { observations }\end{array}$ \\
\hline Fiscal surplus & 0.30 & $-0.25(0.11)$ & 59 \\
Foreign currency bond rating & 0.37 & $-0.20(0.08)$ & 58
\end{tabular}

NOTE: "Foreign currency bond rating" from Standard \& Poor's, January 2000; "fiscal surplus" from International Financial Statistics. Heteroskedastic-consistent standard errors are in parentheses; ${ }^{* * *},{ }^{* *}$, and ${ }^{*}$ indicate significance at the 1,5 , and 10 percent levels, respectively.

leads to both increased transparency and lower average inflation, then we might expect it to lead also to improvements in other policy outcomes that are exogenous to inflation. For example, in many countries dramatic turnarounds in economic policy often involve both reductions in inflation and improvements in a government's fiscal balance, to the extent that fiscal balance can be seen as being exogenous to inflation. Likewise, a policy turnaround is also likely to lead to an improvement in the rating on a government's foreign currency bonds, which should be independent of domestic inflation. This suggests using the fiscal balance and the rating on foreign currency-denominated bonds in order to proxy for $x$. We can then perform the same test that we performed for variables such as "democracy." Table 7 shows the results, while also showing the simple correlation of each variable with the Guttman scale. The results strongly suggest that our original results with respect to transparency and inflation cannot be attributed entirely to broader policy improvements.

We also considered directly the possibility of reverse causality, whereby the negative correlation between transparency and inflation could reflect the fact that central banks are more likely to publish 


\section{Table 8}

\section{Endogeneity of Transparency to Past Inflation and Output Outcomes}

\begin{tabular}{lcc} 
& $\begin{array}{c}\text { Correlation } \\
\text { with Guttman }\end{array}$ & $\begin{array}{c}\text { Coefficient on Guttman } \\
\text { after inclusion }\end{array}$ \\
\hline Past deviation of output from desirable & -0.16 & $-0.24(0.10)^{* *}$ \\
Past output volatility & -0.26 & $-0.23(0.09)^{* * *}$ \\
Past deviation of inflation from desirable & -0.42 & $-0.16(0.10)^{*}$ \\
Past inflation volatility & -0.43 & $-0.20(0.11)^{*}$
\end{tabular}

NOTE: "Past deviation of output from desirable" is average absolute deviation from 2 percent real GDP growth over 1990-94. "Past output volatility" is the mean deviation of real GDP growth with respect to the average level of GDP growth. "Past deviation of inflation from desirable" is average absolute deviation from 2.5 percent inflation over 1990-94. "Past inflation volatility" is the log of the mean deviation of inflation 1990-94 with respect to the average level of inflation for the same period. Heteroskedastic-consistent standard errors are in parentheses; ${ }^{* *},{ }^{* *}$, and $*$ indicate significance at the 1, 5, and 10 percent levels, respectively.

forecasts when they have greater control over macroeconomic outcomes. If this assessment is accurate, one would expect central banks to decide whether to make their forecast public based on the level and the volatility of past inflation (and potentially output). A bias would be introduced in our results, then, to the extent that lagged inflation or lagged inflation volatility is correlated with the current level of inflation.

For each of our sample countries using the five years preceding our sample period (1990-94), we calculated the mean absolute deviation of inflation and output from their desirable levels during this same period ( 2 percent inflation and 2.5 percent annual output growth). We also calculated the mean absolute deviation of inflation and output from their average level for the period, in order to measure volatility. As the endogeneity critique would suggest, our Guttman scale for transparency is in fact negatively correlated with lagged inflation outcomes over the 1990-94 period (see Table 8). We then included each of these four measures as control variables in regressions using the specification from regression (3) in Table 8. As can be seen in Table 8, the coefficient on the Guttman scale is essentially unchanged when we control for both lagged output and lagged output volatility. However, when we control for lagged inflation and lagged inflation volatility, the coefficient on the Guttman scale is less negative and somewhat less significant in each case $(p=0.10$ and $p=0.07$ ). The reduction in the significance of the coefficient after the inclusion of lagged inflation is to some extent inevitable. Lagged inflation is itself likely to have been caused partly by lagged trans parency, measures of which are not at our disposal. So although we acknowledge that it is difficult to be certain that there is not some endogeneity between transparency and inflation, we are reassured that the association is clearly detectable even when we control for the effect of the average rate or volatility in past output and inflation.

\section{Other Robustness Issues}

We also considered several other robustness issues, including whether or not our results are stable when we consider subsamples of low-inflation countries, whether changes in the time period affect the results, and whether modifications in the Guttman scale lead to significantly different inferences.

In addition to investigating outliers, we also determined the extent to which our results are robust with regard to modification of the time period considered. When we performed regressions based on inflation data for individual years between 1995 and 1999, the coefficient on our transparency index was always negative and generally statistically significant at conventional levels. ${ }^{39}$

We also examined the possibility that the Guttman scale might not be the most appropriate technique for examining the relationship between average inflation and the transparency indicators collected as part of the FJMRS survey. We compared the results of our regressions using a Guttman scale with two alternative specifications. The first alternative was to take the simple average of the four

\footnotetext{
39 Coefficients and standard errors for each successive year were -0.29 $(0.10)$ for $1995,-0.15(0.17)$ for $1996,-0.30(0.09)$ for $1997,-0.28$ (0.21) for 1998 , and $-0.41(0.20)$ for 1999.
} 
indicators. To test which of the two specifications (Guttman vs. average) provided more explanatory power, we used a simple non-nested test developed by Davidson and MacKinnon (1981); the test results supported using the Guttman scale. ${ }^{40}$

The second alternative to the existing Guttman scale involved creating a matrix of dummy variables, each of which takes a value of 1 for a particular range of values of the Guttman scale. This method allows the estimated effect of each step on the Guttman scale to vary, whereas introducing the Guttman scale as a single variable constrains the estimated effect of each successive step upward on the Guttman scale to be constant. Our sample countries can be divided into three groups of roughly equal size for this purpose. First, there are 25 countries that do not publish any form of inflation forecast (Guttman $=0$ ). Second, there are 32 countries that publish a basic forecast that, in most cases, includes forward analysis on at least an annual basis (Guttman $=1$ to 2). Finally, there is a third group of 25 countries that publish an inflation forecast including a discussion of previous forecast errors and, in most cases, a discussion of risks to the forecast (Guttman $=3$ to 4 ).

We repeated regression (2) from Table 3, while substituting two dummy variables for the Guttman scale: one for countries with Guttman values of 1 and 2 , and the other for countries with Guttman values of 3 and 4. Both dummy variables had the expected negative sign, and the dummy for Guttman values of 3 and 4 was both more negative and more statistically significant than the dummy for Guttman values of 1 and $2 .{ }^{41}$ These results suggest that while there may be significant gains from publishing a basic inflation forecast, the marginal gain in terms of inflation performance from publishing a more detailed forecast may be even larger. It should be noted, though, that because the coefficient on the dummy for Guttman values of 1 and 2 was not highly significant, using a standard F test, we were unable to reject the null hypothesis that the coefficients on the two dummies were equal.

A final potential robustness issue involves the measurement of our dependent variable. While much of the cross-country literature on determinants estimates a semi-log model which minimizes the effect of high-inflation outliers, Bleaney (1999) argues that using log inflation as a dependent variable results in too much weight being given to countries with very low inflation. As an alternative, he suggests estimating an equation where the dependent variable is $\left(\pi_{i}\right) /\left(1+\pi_{i}\right)$, where $\pi_{i}$ is inflation in the $i$ th country. All of our results from Table 3 remain robust when we use transformed inflation instead of log inflation as our dependent variable. As a further alternative, we also repeated our Table 3 regressions using a Box-Cox model, and the results of this estimation were nearly identical to our original semi-log specification.

\section{Our Bottom Line on Robustness}

We have subjected our results to numerous econometric tests, and they remain reassuringly robust. But how far have we gone in explaining the apparent empirical conundrum we highlighted at the start of the section - that few central banks publish forecasts in full detail in spite of the evidence that such acts would facilitate lower inflation? Although we have controlled for a number of additional variables in this section, it remains possible that the negative correlation we observe between transparency and inflation is biased by our inability to control for unobserved country effects.

To be absolutely confident that our results are subject to zero econometric bias, we would need more data. To eliminate the possibility of reverse causality affecting our results, for example, we would need to distinguish those central banks that were publishing forecasts merely to rubber-stamp their reputation, and those that were reluctant to publish because inflation was high. Such causality analysis would benefit from a time series or panel data on transparency, yet so far these data are unavailable. We feel comforted, however, that we know of no example of a framework in which policymakers have reduced transparency in response to an increase in inflation. Furthermore, to the extent that transparency locks in low-inflation policies even if it is introduced when inflation is already low, then

\footnotetext{
40 The J test involves estimating each specification and saving the fitted values as a first step. Then, in the second step the fitted values from each specification are included as an additional explanatory variable in the alternative specification. The t statistic on the coefficient for the fitted values can then be used as a test of the null hypothesis that the alternative specification does not add any explanatory power. Using this test we rejected the null hypothesis that the Guttman specification did not add explanatory power to the "average" specification. In contrast, we could not reject the null hypothesis that the "average" specification does not add explanatory power to the Guttman specification.

41 The coefficient (and standard error) for the dummy Guttman values of 1 and 2 was $-0.48(0.38)$. The coefficient for the dummy Guttman values of 3 and 4 was both larger and highly statistically significant: -0.98 (0.37), $\mathrm{p}<0.01$
} 
the issue of reverse causality becomes less important, since transparency may be effective in reducing and maintaining low inflation.

Of greater practical relevance could be the possibility that some central banks have attempted to improve macroeconomic policy by simultaneously altering policy preferences, transparency, and other aspects of the institutional framework, which could be argued to be the case in some inflation-targeting countries. ${ }^{42}$ Cukierman (2000c) develops a model where there is a possibility of a policymaker being dependable or weak, yet inflation control errors are sufficiently large to offer weak policymakers a possible cloak of disguise. Dependable policymakers like to raise the probability of being revealed as such, whereas opportunistic policymakers like to reduce the probability of being revealed as weak. An interpretation of his results is that a decision to become transparent and a decision to become dependable may be observationally inseparable. Even with good time-series data, it would be difficult to identify the precise empirical role of transparency in such circumstances, yet our conclusion that publishing forecasts can lead to lower inflation is unaffected by this sort of endogeneity.

Overall, we acknowledge that in spite of the battery of tests we employ, we cannot be sure that our tests using cross-section data eliminate all possible biases. Yet our existing tests have gone far enough to make us confident that we have identified empirically an established theoretical channel for attaining and maintaining low inflation. Furthermore, there are important global policy implications: many central banks around the world could secure improved credibility and lower inflation by publishing their forecasts in greater detail.

\section{CONCLUSION}

There are a number of aspects to central bank transparency, yet recent theoretical models and much of the policy debate focus on the role of the publication of central bank forecasts. The existing literature provides mixed suggestions and evidence on the welfare effects of monetary policy transparency. It is virtually unanimous, however, about the main proposition tested in this paper: greater transparency in monetary policy leads to lower inflation. Furthermore, one of the most important channels identified by the theoretical literature is entirely consistent with the practical experiences of the numerous central banks that have chosen to explain policy more thoroughly: transparency makes a central bank's credibility more sensitive to its actions.

This paper is the first to consider detailed crosscountry evidence for a wide range of countries covering the effects of central bank transparency on monetary policy outcomes. We construct an index of central bank transparency based on forecast publications by central banks. The main empirical result is that greater transparency in publishing forecasts is associated with lower inflation. We acknowledge that it is difficult to be certain that there is not some endogeneity between transparency and inflation. We are, however, reassured that the result is robust to a comprehensive set of econometric specifications and robustness checks, and the association between transparency and inflation is detectable even when we control for the effect of the average inflation rate or volatility in past output and inflation.

Our results suggest that transparency contributes to lower inflation whether or not policy is based more on an inflation-targeting or money-targeting anchor for policy. In countries that target the exchange rate, the publication of forecasts does not appear to have a significant impact on inflation. Finally, we do not find evidence supporting the proposition that a high degree of transparency is associated with higher output volatility.

\section{REFERENCES}

Beck, Thorsten; Clarke, Anthony; Groff, Alberto; Keefer, Phillip and Walsh, Patrick P. "Database on the Institutions of Government Decision Making.” Unpublished manuscript, Development Research Group, The World Bank, 1999.

Bleaney, Michael. "The Disappearing Openness-Inflation Relationship: A Cross-Country Analysis of Inflation Rates.” Working Paper No. 99/161, International Monetary Fund, December 1999.

Blinder, Alan S. "Central Bank Credibility: Why Do We Care? How Do We Build It?” American Economic Review, 2000, 90(5).

; Goodhart, Charles A.E.; Hildebrand, Philipp; Lipton, David and Wyplosz, Charles. "How Do Central Banks Talk?" Centre for Economic Policy Research, October 2001.

Briault, Clive B.; Haldane, Andrew G. and King, Mervyn A.

${ }^{42}$ See Schaecter, Stone, and Zelmer (2000). 
"Independence and Accountability." Working Paper No. 49, Bank of England, April 1996.

Buiter, Willem. "Alice in Euroland." Journal of Common Market Studies, June 1999, 37(2), pp. 181-209.

Canzoneri, Matthew B. "Monetary Policy Games and the Role of Private Information." American Economic Review, December 1985, 75(5), pp. 1056-70.

Campillo, Marta and Miron, Jeffery A. "Why Does Inflation Differ Across Countries?” Working Paper No. 5540, National Bureau of Economics Research, 1996.

Canavan, Chris and Tommasi, Mariano. "On the Credibility of Alternative Exchange Rate Regimes.” Journal of Development Economics, October 1997, 54(1), pp. 101-22.

Chortareas, Georgios E.; Stasavage, David and Sterne, Gabriel. "Monetary Policy Transparency, Inflation and the Sacrifice Ratio." International Journal of Finance and Economics, 2002 (forthcoming)

Clare, Andrew and Courtenay, Roger. "Assessing the Impact of Macroeconomic News Announcements on Securities Prices Under Different Monetary Policy Regimes." Working Paper No. 125, Bank of England, February 2001.

Cukierman, Alex. "Are Contemporary Central Banks Transparent About Economic Models and Objectives and What Difference Does It Make?” Working paper, Tel-Aviv University, 2000a.

"Establishing a Reputation for Dependability

by Means of Inflation Targets," in Lavan Mahadeva and Gabriel Sterne, eds., Monetary Frameworks in a Global Context. London: Routledge, 2000b.

"Accountability, Credibility, Transparency and Stabilization Policy in the Eurosystem," in Charles Wyplosz, ed., The Impact of EMU on Europe and the Developing Countries. New York: Oxford University Press, 2001.

and Meltzer, Allan H. "A Theory of Ambiguity, Credibility, and Inflation Under Discretion and Asymmetric Information." Econometrica, September 1986, 54(5), pp. 1099-28.

Davidson, Russell and MacKinnon, James G. “Several Tests for Model Specification in the Presence of Alternative Hypotheses." Econometrica, May 1981, 49(3), pp. 781-93.
Dotsey, Michael. "Monetary Policy, Secrecy, and Federal Funds Rate Behavior." Journal of Monetary Economics, December 1987, 20(3), pp. 463-74.

Faust, Jon and Svensson, Lars E.O. "The Equilibrium Degree of Transparency and Control in Monetary Policy." Discussion Paper No. 2195, Centre for Economic Policy Research, October 2000.

and "Transparency and Credibility: Monetary Policy with Unobservable Goals.” International Economic Review, May 2001, 42(2), pp. 369-97.

Fry, Maxwell J. "Assessing Central Bank Independence in Developing Countries: Do Actions Speak Louder than Words?" Oxford Economic Papers, July 1998, 50(3), pp. 512-29.

; Julius, DeAnne; Mahadeva, Lavan; Roger, Sandra and Sterne, Gabriel. "Key Issues in the Choice of Monetary Policy Framework," in Lavan Mahadeva and Gabriel Sterne, eds., Monetary Frameworks in a Global Context. London: Routledge, 2000.

Geraats, Petra M. "Why Adopt Transparency? The Publication of Central Bank Forecasts.” Working Paper No. 41, European Central Bank, 2001a.

"Transparency of Monetary Policy: Does the Institutional Framework Matter?" Unpublished manuscript, University of Cambridge, 2001b.

Ghosh, Atish R.; Gulde, Anne-Marie; Ostry, Jonathan D. and Wolf, Holger C. "Does the Nominal Exchange Rate Regime Matter?” Working Paper WP/95/121, International Monetary Fund, 1995.

Goodfriend, Marvin. "Monetary Mystique: Secrecy and Central Banking." Journal of Monetary Economics, January 1986, 17(1), pp. 63-92

Haldane, Andrew G. and Read, Vicky. "Monetary Policy Surprises and the Yield Curve." Working Paper No. 106, Bank of England, 2000.

Herrendorf, Berthold. "Transparency, Reputation, and Credibility Under Floating and Pegged Exchange Rates." Journal of International Economics, 1999, 49(1), pp. 31-50.

International Monetary Fund. Supporting document to the Code of Good Practices on Transparency in Monetary and Financial Policies. Washington, DC: 2000. <www.imf.org/ external/np/mae/mft/sup/index.htm > . 
Issing, Otmar. "The Eurosystem: Transparent and Accountable or 'Willem in Euroland'." Journal of Common Market Studies, September 1999, 37(3), pp. 503-19.

Jensen, Henrik. "Optimal Degrees of Transparency in Monetary Policymaking." Working paper, University of Copenhagen, 2000.

Kohn, Donald. "The Kohn Report on MPC Procedures.” Bank of England Quarterly Bulletin, Spring 2001, pp. 35-54.

Kuttner, Kenneth N. and Posen, Adam S. "Inflation, Monetary Transparency, and G3 Exchange Rate Volatility." Working Paper 00-06, Institute for International Economics, 2000.

Lane, Philip R. "Inflation in Open Economies.” Journal of International Economics, May 1997, 42(3-4), pp. 327-47.

La Porta, Rafael; Lopez-de-Silane, Florencio; Shleifer, Andrei and Vishny, Robert W. "The Quality of Government." Journal of Law Economics and Organization, April 1998, 15(1), pp. 222-79.

Mahadeva, Lavan and Sterne, Gabriel, eds. Monetary Frameworks in a Global Context. London: Routledge, 2000.

and "Inflation Targets as a

Stabilisation Device.” The Manchester School, 2002 (forthcoming).

Masson, Paul R.; Savastano, Miguel A. and Sharma, Sunil. "The Scope for Inflation Targeting in Developing Economies.” Working Paper No. 97/130, International Monetary Fund, October 1997.

Mishkin, Frederic S. "Inflation Targeting for EmergingMarket Countries." American Economic Review Papers and Proceedings, May 2000, 90(2), pp. 105-09.

and Schmidt-Hebbel, Klaus. "A Decade of Inflation Targeting in the World: What Do We Know and What Do We Need to Know?" in Norman Loayza and Raimundo Soto, eds., Inflation Targeting: Design, Performance, Challenges. Santiago: Central Bank of Chile, 2002.

Morris, Stephen and Shin, Hyun-Song. "Welfare Effects of Public Information.” Unpublished manuscript, Cowles Foundation, Yale University, January 2001.

Nolan, Charles and Schaling, Eric. "Monetary Policy Uncertainty and Central Bank Accountability." Working Paper No. 54, Bank of England, October 1996.
Peek, Joe; Rosengren, Eric S. and Tootell, Geoffrey M.B. "Does the Federal Reserve Have an Informational Advantage? You Can Bank on It.” Working Paper No. 98-2, Federal Reserve Bank of Boston, April 1998.

and "Does the Federal Reserve Possess an Exploitable Informational Advantage?" Working Paper No. 99-8, Federal Reserve Bank of Boston, 1999.

Posen, Adam S. "Lessons from the Bundesbank on the Occasion of Its Early Retirement," in Lavan Mahadeva and Gabriel Sterne, eds., Monetary Frameworks in a Global Context. London: Routledge, 2000.

Romer, David H. "Openness and Inflation: Theory and Evidence." Quarterly Journal of Economics, November 1993, 108(4), pp. 869-903.

Romer, Christina D. and Romer, David H. "Federal Reserve Information and the Behavior of Interest Rates." American Economic Review, June 2000, 90(3), pp. 429-57.

Schaecter, Andrea; Stone, Mark R. and Zelmer, Mark. "Adopting Inflation Targeting: Practical Issues for Emerging Market Countries." Occasional Paper No. 202, International Monetary Fund, December 2000.

Stein, Jeremy C. "Cheap Talk and the Fed: A Theory of Imprecise Policy Announcements." American Economic Review, March 1989, 79(1), pp. 32-42.

Sterne, Gabriel. "Inflation Targets in a Global Context," in Norman Loayza and Raimundo Soto, eds., Inflation Targeting: Design, Performance, Challenges. Santiago: Central Bank of Chile, 2002.

Svensson, Lars E.O. "Independent Review of the Operation of Monetary Policy in New Zealand: Report to the Minister of Finance." < http://www.princeton.edu/ svensson/NZ/ RevNZMP.htm > , 2001.

Tarkka, Juha and Mayes, David G. "The Value of Publishing Official Central Bank Forecasts.” Discussion Paper 22/99, Bank of Finland, 1999.

Thornton, Daniel L. "The Fed's Influence on the Federal Funds Rate: Is It Open Market or Open Mouth Operations?" Presented at The Bundesbank/CFE Conference Transparency in Monetary Policy, October 1999.

Winkler, Bernhard. "Which Kind of Transparency? On the Need for Clarity in Monetary Policy-Making." Working Paper No. 26, European Central Bank, August 2000. 
